\title{
Anosov 映射的周期点数
}

Anosov 映射是以紧致度量空间作状态 空间的, 保持局部乘积结构的连续满映射. 它等价于具有伪轨跟踪性质的可扩自映射. 关于 Anosov 映射的周期点和周期, 已知的 结果有, 周期点在非游荡集中稠密, $n$ 周期点 数有限和用 $n$ 周期点数构造的 $\zeta$ - 函数有 理. 本文进一步讨论 $n$ 周期点数. 用指数函 数和幕函数给出了 $n$ 周期点数的上下界.

设 $(X, f)$ 为 Anosov 映射形成的离散系 统, 即 $f$ 为 $X$ 到自身的满足伪轨跟踪条件的 可扩的连续满射,而 $X$ 是紧致度量空间．存

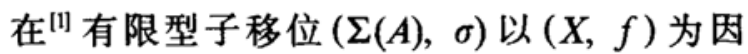
子 (factor) 即存在连续满映射 $\rho: \Sigma(A) \rightarrow X$, 使得, $\rho \cdot \sigma=f \cdot \rho$. 用 $N_{n}(\cdot)$ 记自映射或自 同胚的 $n$ 周期点数.

定理 1 设 $(X, f)$ 为 Anosov 映射形成 的系统, 则存在正整数 $L$ 和 $m$ 满足

$$
L N_{n}(f) \geqslant N_{n}(\sigma), N_{n}(f) \leqslant N_{n m}(\sigma) .
$$

讨论Specification 性质和引用 Smale-
Bowen 分解定理 ${ }^{[2]}$ 可以证明

定理 2 设 $(X, f)$ 为 Anosov 映射形成 的系统, 若非游荡集 $\Omega(f)$ 无限, 则 $(X, f)$ 具 正的拓扑嫡.

定理 3 设 $(X, f)$ 为 Anosov 映射形成 的系统, 若非游荡集 $\Omega(f)$ 无限, 则存在正整 数 $M$ 和 $H$ 满足

$$
n^{M} \leqslant N_{n}(f) \leqslant H^{n},
$$

这里 $n$ 趋于正无穷.

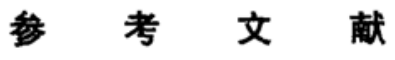

[1] Sakai, K., J. Math. Soc. Japan, 1987, 39 (3): $505-519$.

[2] Sun Wen-xiang (孙文样), Chinese Sci. Bull., 1991, 36: $1948-1951$.

\section{纳米尺寸的氮化镁的合成}

催化合成的氢化镁 $\left(\mathrm{MgH}_{2}\right)$ 作为储氢材 料, 在吸放氢动力学性能以及在有机和无机 合成反应中的应用等方面, 明显优于高温高 压下合成的 $\mathrm{MgH}_{2}^{[1-3]}$. 在研究掺杂对催化 合成 $\mathrm{MgH}_{2}$ 及其性能的影响的实验中 ${ }^{[4]}$, 我们 发现催化合成的 $\mathrm{MgH}_{2}$ 在氮气氛下的差热分 析 (DTA) 曲线于 $\mathrm{MgH}_{2}$ 的脱氢吸热峰后出 现一个放热峰, 峰值为 $5677^{\circ} \mathrm{C}$, 其后不再有 镁的熔化吸热峰; 在氢气氛下进行 DTA 测 量, 则无上述放热峰. 这就意味着催化合成 的 $\mathrm{MgH}_{2}$ 热分解脱氢后得到的高活性锫粉
$\mathrm{Mg}^{++}$, 在氮气氛中进行氮化反应的温度会显 著低于文献报道的合成 $\mathrm{Mg}_{3} \mathrm{~N}_{2}$ 的温度 ${ }^{(?)}$.

我们在常压、 $450^{\circ} \mathrm{C}$ 条件下, 分别进行了 工业镁粉 $\left(100-200\right.$ 目) 和 $\mathrm{Mg}^{++}$的曶化反 应实验. 前者反应 $23 \mathrm{~h}$, 吸氮量仅为理论值 的 $1 \%$. 后者反应 $18 \mathrm{~h}$, 吸氮量为理论值的 $81 \%$. 上述实验结果表明, $\mathrm{Mg}^{++}$在 $450^{\circ} \mathrm{C}$ 的 氮化反应速度不仅远高于工业镁粉, 而且也 显著高于文献报道的电离辐射促进的金属镁 粉 (比表面 $\left.0.9 \mathrm{~m}^{2} / \mathrm{g}\right)$ 的氮化反应速度 $(450$ ${ }^{\circ} \mathrm{C}$ 反应 $18 \mathrm{~h}$, 吸氮量为理论置的 $\left.14 \%\right)^{6 \text {. }}$. 
我们在实验中还发现, 掺杂过渡金属可 使 $\mathrm{Mg}^{++}$体系的氮化反应速度进一步加快; 掺杂物种不同, 氮化反应速度提高的程度亦 不同. 如掺杂物种为二氯二茂钩 (掺杂量为 $2.5 \mathrm{~mol} . \%$ ) 时, 掺杂 $\mathrm{Mg}^{++}$体系在 $450{ }^{\circ} \mathrm{C}$ 与 氮反应 $8 \mathrm{~h}$, 吸氮量为理论值的 $94 \%$; 反应 $18 \mathrm{~h}$, 吸曶量达到理论值的 $99 \% . \mathrm{Mg}^{++}$体系 吸氛后样品的 XRD 谱图显示出 $\mathrm{Mg}_{3} \mathrm{~N}_{2}$ 的特 征峰. 透射电镜测量结果表明, 用 $\mathrm{Mg}^{++}$合 成的 $\mathrm{Mg}_{3} \mathrm{~N}_{2}$ 的平均颗粒直径为 $14 \mathrm{~nm}$.

$\mathrm{Mg}_{3} \mathrm{~N}_{2}$ 在制备具有高硬度、高热导和抗 腐蚀、抗磨损、耐高温性质的其它元素的氮 化物及制备特殊陶瓷材料等方面有许多应 用; $\mathrm{Mg}_{3} \mathrm{~N}_{2}$ 还可用作制备特种合金的发泡剂 及用于回收核废料等. 初步的实验现象表 明, 使用 $\mathrm{Mg}^{++}$合成的纳米尺寸的 $\mathrm{Mg}_{3} \mathrm{~N}_{2}$ 具 有很高的反应活性, 预示着其可能会有湈新 的应用范围. 进一步的实验研究工作正在进 行之中。

\section{参考文 献}

[1] Bogdanovic, B., Liao Shi-jian, Schwichardi, M. et al., Angew. Chem., 1980, 92:845.

[2] Lin Gen-wen, Liao Shi-jian, Xu Yun et al., Chinese Chem. Lett., 1993, (4): 543.

[3] Bartmann, E., Bogdanovic, B., Janke, N. et al., Chem. Ber., 1990, 123: 1517.

[4] 崔屾、装世健、徐筇, 中国专利, 94110129.

[5] Helmar, L., Ulrick, K., Christian, H. et al., J. Mater. Sci. Lett., 1988, (7): 23.

[6] Fomin, O. K., Isakov, I. V., Triskkin, A. E., High Energy Chem., 1985, 19:406.

崔 屾塺世健 徐 笏 (中国科学院大连化学物理研究所, 大连116023)

苗延芬李新生李大明 (中国科学院大连化学物理研究所国家催化基础 重点实验室, 大连116023)

陆 敏 范荫恒 郭文生

(辽宁师范大学, 大连116022)

\section{青藏高原古里雅冰芯中的现代大气环境记录 *}

1992 年在西昆仑山古里雅冰帽海拔 $6400 \mathrm{~m}$ 处钻取的古里雅冰芯 ${ }^{[1]}$, 连续记录了 大气对流层中上部气溶胶的干、湿沉积, 为 研究青藏高原西北部高空大气环境提供了独 特的契机. 根据对冰帽的粒雪成冰和冰内化 学物质的沉积过程以及冰芯物理学研究, 现 已探明冰芯内主要特征层位的形成机制和季 节. 高粉尘季节冰层 (污化层): 主要形成在 2-5 月份西部 “尘暴”频发的高粉尘季节 (由于钻孔处夏季融水很少而且冻结迅速, 极少促成夏末污化层的形成); 低粉尘季节 冰层 (透明冰层): 形成在夏季的高原低粉尘 季节. 其余层位多为气泡富集的白冰. 根据污 化层定年结果, 冰芯上部 $5 \mathrm{~m}$ 系 1977-1992
年间的降水净积累, 我们利用其中特征层位 水样品的 6 种基本化学离子 $\left(\mathrm{Na}^{+}, \mathrm{Ca}^{2+}\right.$, $\mathrm{Mg}^{2+}, \mathrm{Cl}^{-}, \mathrm{SO}_{4}^{2-}, \mathrm{NO}_{3}^{-}$) 浓度测定资料, 对 其所包含的气溶胶记录进行了恢复. 主要结 果如下:

(1)各种阴 (阳) 离子浓度的深度曲线存 在十分明显的线性相关关系, 均表现出强烈 的周期性变化特征 (图 1). 6 种离子在高粉 尘季节冰层中的平均浓度值为低粉尘季节冰 层的 4-8 倍不等. 这一结果说明青藏高原西 北部大气环境存在很大的季节差异. 低粉尘 季节冰层中的 $\mathrm{SO}_{4}^{2-}, \mathrm{NO}_{3}^{-}$含量平均值分别 为 1.6 和 $1.3 \mu \mathrm{mol} / \mathrm{kg}$, 与当代全球偏远地区 (remotearea, 即远离人类主要活动区) 雪冰 